\section{The Acutely III Child: A Ready Reckoner}

\footnotetext{
$\mathrm{T}$
} he acutely ill child presents a significant diagnostic and management challenge to the child care provider. A satisfactory outcome depends on the rapid provision of evidence based appropriate treatment. This lucidly written handbook provides all the immediately required necessary information in an algorithmic format and is likely to be very useful as a quick reference at the first point of contact. While there are many books on paediatric emergency care, this particular ready reckoner with its easy readability would be extremely handy as a lot of relevant information is packed in just a page or two for an individual emergency. The handbook has been divided into various sections such as supporting the sick child followed by sections on different systems which includes respiratory, cardiovascular, hemato-oncology, endocrine, renal, GIT, liver, neurology, IEM, and toxicology. These sections are followed by chapters on common procedures. The most interesting feature is the well compiled set of appendices covering most of the charts and scales routinely looked at during the care of a sick child. The book is also unique with respect to its contributors who are mostly residents assisted by faculty from the department of Paediatrics at Armed Forces Medical College. It's essentially a handbook by the residents and for the residents. In addition, this concise handbook is also likely to be very useful for the medical officers or nurses apart from the practicing paediatrician. Overall, the book is simple and yet impressive and a must have 'Ready reckoner'.

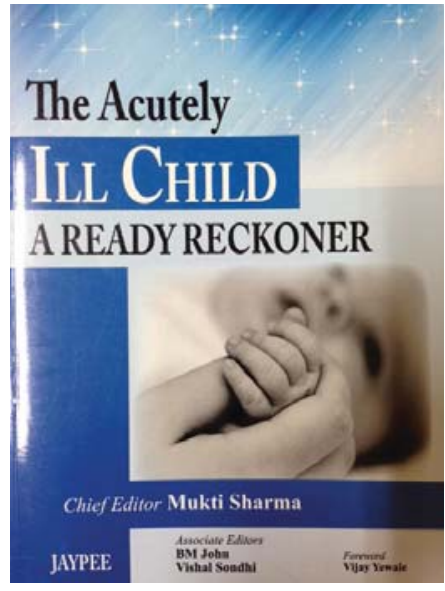

JayPee Publications, New Delhi, Pages-349, Price: INR 495/

Editors: Dr. Mukti Sharma, MD, DNB, FCSI, FIAP, Consultant \& HOD-Paediatrics, Army Hospital(R\&R), Delhi Cantt. Dr. BM John, MD, Associate Professor-Pediatrics, AFMC, Pune. Dr. Vishal Sondhi, MD, Associate Professor-Paediatrics, AFMC, Pune, India.

This work is licensed under a Creative Commons Attribution 3.0 License. 